\title{
CONFECÇÃO DE BOLSAS A PARTIR DO REAPROVEITAMENTO: UM OLHAR DIFERENTE SOBRE O BANNER
}

\author{
Cássia de Paula Freitas da Silva ${ }^{1}$ \\ Gysele Maria Morais Costa ${ }^{2}$ \\ Larissa Sales da Costa Oliveira ${ }^{3}$ \\ Juliana Pires dos Santos Nascimento ${ }^{4}$ \\ Natália da Silva Araújo ${ }^{5}$ \\ André Silva dos Reis ${ }^{6}$
}

Resumo: O pôster (ou banner) é muito utilizado no Brasil para apresentações cientificas, todavia, há um grande impacto ambiental gerado pelo descarte inadequado. Assim, o objetivo deste artigo foi reaproveitar os banners a partir da confecção de bolsas. O desenvolvimento deste trabalho se deu por meio de uma oficina dividida em dois momentos: I) conceitos, curiosidades acerca da temática e II) confecção de bolsas de banner. Ao término da oficina, aplicou-se um questionário versando sobre o aspecto socioambiental e papel da universidade, fez-se o uso da análise de conteúdo para a interpretação das respostas. Constatou-se que a oficina contribuiu para aprofundamento dos conhecimentos, reflexão ambiental e novas estratégias de ensino de química.

Palavras-chave: Impacto Ambiental; Banner; Ensino de Química; Confecção de Bolsas.

\footnotetext{
1 Universidade do Estado do Pará. E-mail: cassiafreitas33@yahoo.com.br

2 Universidade do Estado do Pará. E-mail: gyselemorais@hotmail.com

3 Universidade do Estado do Pará. E-mail: larissa.sales44@gmail.com

${ }^{4}$ Universidade do Estado do Pará. E-mail: juliana-piress@hotmail.com

${ }^{5}$ Universidade do Estado do Pará. E-mail: nathyarauj019@gmail.com

6 Universidade Federal do Pará. E-mail: andre.reis@uepa.br
} 


\section{Introdução}

O lixo produzido antes da Revolução Industrial era composto apenas de matéria orgânica. Após esse advento, o impacto ao meio ambiente foi acentuado em decorrência da atividade humana, através da exploração de recursos naturais, a geração de grandes quantidades de resíduos sólidos e o descarte inapropriado dos mesmos, sendo o plástico um dos principais resíduos (SILVA; SANTOS; SILVA, 2013).

Segundo a Associação Brasileira de Empresas de Limpeza Pública e Resíduos Especiais (ABRELPE) o consumo de plásticos no Brasil, em 2015, atingiu 6,99 milhões de toneladas. Para a Braskem, uma organização das empresas Obedrecht e Grupo Mariani, considerada a maior produtora de resinas termoplásticas, ressalta que a produção de resinas de PVC, em 2015, atingiu 542 mil toneladas. A maioria das resinas transformadas para o consumo final se encontra nos setores de construção civil, agricultura, automóveis e autopeças (ABIPLAST, 2014) ${ }^{7}$.

Os pôsteres ou painéis também conhecidos pelo termo inglês banners é constituído por fibras sintéticas chamada de policloreto de viníla (PVC). É um tipo de polímero proveniente do petróleo apresentando uma baixa biodegradabilidade, ou seja, são necessários 400 anos para se decompor na natureza (BRASIL, 2005). No Brasil é comumente usado para a divulgação científica e publicitária por apresentar um baixo custo, consequentemente a larga utilização deste material aumenta o descarte em lixos comuns da cidade prejudicando o meio ambiente (OJEDA, 2008).

Rocha, Rosa e Cardoso (2009) afirmam que a tecnologia permitiu o melhoramento da produção de banners, e atualmente é possível encontrar materiais altamente resistentes a calor, umidade e com impressão em alta definição como a lona de vinil. Para minimizar os impactos ambientais causados pelo destino inadequado de banners de viníla é possível reaproveitar esse material para confecção de novos produtos, como bolsa, estojos e sacolas. A ideia de reaproveitamento surge aliada aos conceitos de reduzir e reutilizar.

Ponderar sobre a degradação ambiental é questionar sobre a ligação entre um problema social que tenta perceber a complexidade que abrange o ser humano e sua influência com o meio. No entanto, a solução se encontra no próprio ser humano, o qual passa pelo campo educacional e pelo investimento em políticas públicas (MENDES, 2009).

Por isso, entende-se que para preservar o meio ambiente é necessário que a sociedade e escolas participem ativamente de ações de Educação Ambiental (EA). Para Mikhailova (2004, p. 25) "uma sociedade sustentável é aquela que não coloca em risco os elementos do meio ambiente".

\footnotetext{
${ }^{7}$ Associação Brasileira da Indústria do Plástico
}

revista brasileira 
De acordo com Cardoso et al. (2016) faz-se necessário o uso da criatividade para tornar útil o que seria descartado e agregar valor ao "lixo", possibilitando benefícios para o meio ambiente e a população.

Diante disso, este projeto executou uma oficina com objetivo de reaproveitar os banners para confecção de bolsas, partindo do pressuposto que a não destinação correta do material, por exemplo, em lixos comuns, contribuirá para o aumento dos impactos ambientais. Além disso, discute-se o papel da universidade atrelada ao ensino de química como forma de propagação de conhecimento e informação para a comunidade.

\section{Uma breve história da Educação Ambiental no Brasil}

Desde a antiguidade a Educação Ambiental já era exercida visto que o homem primitivo utilizava o meio ambiente como principal instrumento de sobrevivência, pois era dessa forma que conseguia alimentos para seu sustento. Nesse sentido, existiam técnicas e cuidados gerados e realizados com a natureza, sendo repassados para filhos de geração em geração. Portanto, dessa forma a Educação Ambiental era praticada e respeitada (REIS, 2005).

A expressão Educação Ambiental (EA) surgiu em 1970 com a proposta de preservar recursos naturais e a qualidade de vida, bem como, adotar políticas educacionais relacionados ao meio ambiente. Os problemas sociais e ambientais, como geração de resíduos, agravaram-se com o advento da Revolução Industrial que visavam apenas o lucro em detrimento da degradação ambiental (REIS, 2005).

No Brasil, em 27 de abril de 1999 criou-se a Lei da Educação Ambiental (no 9.795) que afirma que a educação ambiental é um componente essencial e de tema interdisciplinar para o processo educativo para instituição formal e não formal de ensino (BRASIL, 1999). Além disso, o conceito Educação Ambiental pode ser compreendido por:

[...] processos por meio dos quais o indivíduo e a coletividade constroem valores sociais, conhecimentos, habilidades, atitudes e competências voltadas para a conservação do meio ambiente, bem de uso comum do povo, essencial à sadia qualidade de vida e sua sustentabilidade (BRASIL, Art 1르, 1999).

Diante disso, de acordo com a Política Nacional de Educação Ambiental torna-se necessário na educação nacional um componente importante e frequente que é a educação ambiental tendo vista que a mesma deve ser trabalhada em todo processo educativo de forma estruturada para seja atendida ao seu amplo sentido (BRASIL, 1999).

Atualmente, a compreensão da sociedade é refletida por meio da utilização e execução da educação ambiental, pois é uma prática educativa 
contínua de sua realidade mundial, realidade essa que é traduzida por meio da relação entre os homens e natureza tal como, os problemas e suas causas (PINHEIRO et al., 2011).

Nesse sentido, os projetos ambientais incumbidos por universidades, órgãos públicos e empresas têm o intuito de mobilizar, repensar e mudar hábitos que, de alguma maneira, afetam negativamente a comunidade e seu entorno. A questão ambiental é uma vertente importante para abordar temas de redução, reutilização e reciclagem (3R's) de resíduos sólidos, popularmente conhecido como lixo, para minimizar o desperdício e o despejo impróprio de materiais e produtos (ROCHA; ROSA; CARDOSO, 2009).

Yoshida (2012) ressalta a importância de não gerar como prioridade do Plano Nacional de Resíduos Sólidos - PNRS (2010) e por seguinte a redução, reutilização e reciclagem. A etapa inicial é a redução, pois possibilita a diminuição de geração de resíduos. Por exemplo, substituir copo descartável por copos laváveis. Em seguida, a reutilização do material que seria descartado para diferentes finalidades. A lona vinílica de banner é um exemplo podendo ser utilizado para confecção de bolsas e estojos. E por fim, a reciclagem, que tem o objetivo de aproveitar os resíduos para a produção de um novo produto.

É importante destacar que está cada vez mais presente na sociedade a produção exorbitante de bens materiais e consequentemente a produção de lixo e, ainda o esgotamento dos recursos renováveis. É devido a isto que o homem está dando uma grande significância para a política dos 3R's, visto que, o que antes era considerado produtos inservíveis a reutilização e reciclagem podem torna-lo útil para atingir assim a redução de lixo nas próximas décadas, juntamente com isso implementa-se hábitos de preservação do meio ambiente (PINHEIRO et al., 2011).

\section{O aspecto químico das lonas vinílicas e o descarte incorreto}

Os banners de lonas são encontrados em eventos científicos e materiais de publicidade para diferentes meios de divulgações. Eles são considerados de baixo custo e versátil. No entanto, o banner é composto por um polímero denominado policloreto de viníla (PVC) produzido a partir do petróleo - um recurso não renovável. "As lonas de PVC são produzidas a partir de uma mistura de resina, plastificantes, cargas e aditivos" (JUNG et al., 2015).

Esse polímero apresenta característica de baixa degradabilidade, ou seja, sua decomposição na natureza pode durar centenas de anos para ocorrer (JUNG et al., 2015). Outro fator importante é a interferência na presença da lona para o processo de decomposição da matéria orgânica nos aterros, pois dificulta a troca gasosa devido à formação de camadas impermeáveis impossibilitando a "oxidação biológica do carbono dos resíduos orgânicos" para a realização necessária de microrganismos responsáveis pela decomposição (OLIVEIRA; SATORI; GARCEZ, 2008, p.8). 
Os banners de lona vinílica podem ser considerados resíduos sólidos quando descartados, pois, de acordo com Tavares (2008) os resíduos sólidos, são materiais que possuem valor agregado, pois podem ser utilizados de forma a gerar um potencial econômico respeitável para sociedade podendo ser reciclados, separados ou reaproveitados.

O descarte inadequado de resíduos sólidos possui uma enorme capacidade de prejudicar o meio ambiente e a saúde populacional ocasionando diversas problemáticas debatida no mundo inteiro. O descarte inadequado é todo aquele resíduo depositado no chão, ruas, lagos, praias, rios, praças, escolas e qualquer outro local passivo de ilegalidade (TAVARES, 2008). Para Cardoso et al. (2016) para ajudar a preservar o meio ambiente é necessário observar o tempo de vida e a cadeia de consumo dos produtos, bem como, seu descarte inadequado. No caso particular do banner é válido agregar valor ao reaproveitalo beneficiando o meio ambiente e gerando renda para a população.

São agravantes os problemas ambientais gerados a partir do descarte e acúmulo de resíduos sólidos descartados de maneira inadequada. Assim, é imprescindível que sejam tomadas medidas para que possam evitar problemas relacionados ao ambiente, saúde pública, economia e outros que são afetados devido a essa ação. Essas medidas estão relacionadas ao condicionamento, o tratamento e a disposição final dos resíduos (SANTOS, 2008).

Além do mais, a PNRS propõe em seus instrumentos (Art. 3ํitem XII) a implementação da logística reversa e a caracteriza como:

[...] conjunto de ações, procedimentos e meios destinados a viabilizar a coleta e a restituição dos resíduos sólidos ao setor empresarial, para reaproveitamento, em seu ciclo ou em outros ciclos produtivos, ou outra destinação final ambientalmente adequada (BRASIL, 2010).

Visto nisso, é importante mencionar a necessidade de existir um ponto de coleta do produtor para que as lonas vinílicas tivesse a destinação correta, como a reutilização. A proposta da logística reversa é uma alternativa para minimizar os impactos ambientais causados pelo despejo inadequado do banner.

Portanto, se faz necessário haver algum meio que possibilite conscientizar a população para que haja a diminuição dos resíduos gerados. Então, é por meio da educação ambiental que isso se pode tornar possível, pois, o homem assume um papel de agente transformador, e possibilita um desenvolvimento de habilidades que resulta em um senso de consciência dos demais cidadãos (SANTOS, 2008). 


\section{O papel da universidade no contexto social}

A universidade tem o papel de produzir conhecimento científico e aproximar este conhecimento a realidade de vida da sociedade em geral, tais ações são alcançadas através do tripé da universidade: ensino, pesquisa e extensão. Por meio desse princípio é possível desenvolver ações de responsabilidade e comprometimento social da comunidade com o meio ambiente que vise à promoção da qualidade de vida.

É um problema comum às instituições de ensino o descarte $e$ consequentemente sobra de banners. Devido a isto, essas instituições estão incentivando cada vez mais a reutilização dessas lonas. Assim, surgem projetos de pesquisa e extensão que possuem os objetivos de complementar rendas de comunidades a partir da reutilização desses produtos. É importante destacar que esses projetos estão relacionados a diferentes áreas de conhecimento existentes nas universidades não somente ao curso de Design, tais projetos trabalham com a confecção de mochilas, bolsas e estojos por meio da reutilização de banners de lona (NAJELISKIA; PALHANOB; MATOSOC, 2017).

A partir dos projetos de extensão e integração da sociedade e comunidade científica é possível contribuir para diminuição dos resíduos sólidos gerados, promover a educação ambiental e gerar renda.

\section{Metodologia}

A oficina "Confecção de bolsas a partir do reaproveitamento: Um olhar diferente sobre o banner" foi realizada no VI Simpósio de Estudos e Pesquisas em Ciências Ambientais na Amazônia, no Centro de Ciências Naturais e Tecnologia da Universidade do Estado do Pará, no município de Belém. Este trabalho foi desenvolvido em dois dias, com duração de $2 \mathrm{~h}$ horas cada.

No total foram 20 participantes entre elas graduandos dos cursos de Licenciatura Plena em Ciências Naturais com Habilitação em Química, Física ou Biologia, Bacharelado em Design, professores e profissionais da área ambiental. Desse total $65 \%$ eram mulheres, $20 \%$ homens e $15 \%$ não informaram seu sexo, entre idade de 19 a 60 anos.

A oficina, que acarretou nesse artigo, foi desenvolvida em dois momentos. Inicialmente foram apresentados o conceito, tipos e curiosidades sobre polímeros. Em seguida, se explicou a composição da lona vinílica (banners), a problemática do descarte inadequado e as consequências para 0 meio ambiente. Por fim, utilizou da temática Educação Ambiental (EA) para expor Organizações Não Governamentais (ONGs) que usam mão de obra de presidiários ou pessoas de baixa renda para reaproveitar os banners para promover a responsabilidade socioambiental. Nessas etapas, cada aluno participante pode expor suas experiências e conhecimentos sobre o tema.

Além disso, no último dia ocorreu a confecção das bolsas. Os banners foram disponibilizados pelas ministrantes e pelos participantes da oficina. Os 
participantes seguiram passo a passo para a confecção da bolsa com auxílio das ministrantes (Figura 1). Os materiais utilizados foram tesoura, grampeador, cola tekbond, régua e caneta.

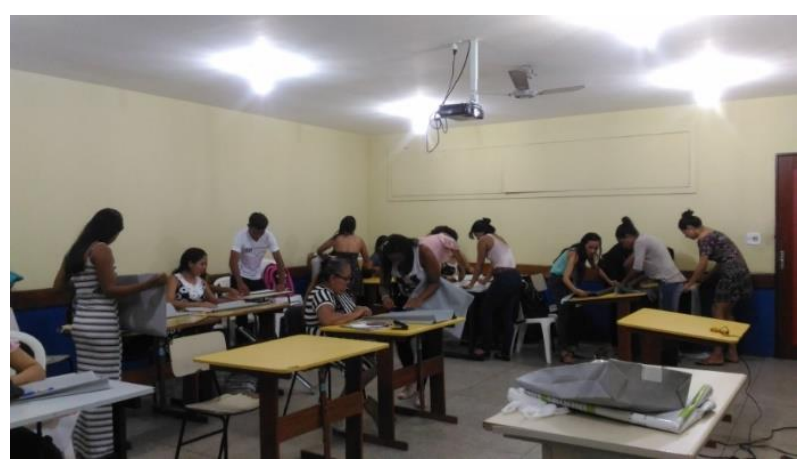

Figura 1: Confecção da bolsa

Fonte: Os autores

Após a confecção, aplicou-se um questionário com quatro afirmativas, que tiveram o objetivo de tratar o aspecto socioambiental e o papel das universidades atrelado ao nível de concordância, onde os participantes deveriam de forma objetiva assinalar seu nível de concordância e ao final justificar de forma discursiva.

A metodologia empregada foi a Análise de Conteúdo, onde são interpretadas as descrições, quantitativa e qualitativa, para um nível de compreensão de características além da leitura (BARDIN, 2011; MORAES, 1999).

As quatro afirmativas foram classificadas em duas categorias, Educação Ambiental e o Papel das Universidades. Duas afirmativas integraram a categoria EA por apresentar características e objetividade referente à temática. As outras duas afirmativas compõem a categoria Papel das Universidades, pois ela tem a responsabilidade de formar pessoas conscientes e divulgar informações. Nesse sentido, a análise qualitativa teve o objetivo de interpretar, contextualizar e discutir as falas dos participantes.

\section{Resultados e discussão}

A análise quantitativa do nível de concordância (concordo totalmente, concordo parcialmente, discordo totalmente, discordo parcialmente e indiferente) para cada categorização a análise foi realizada uma média das respostas das duas afirmativas, apresentada na Tabela 1. Para melhor compreensão dos resultados do estudo, as respostas dos participantes foram agrupadas em duas categorias. 
Tabela 1. Média de respostas de nível de concordância de cada categoria.

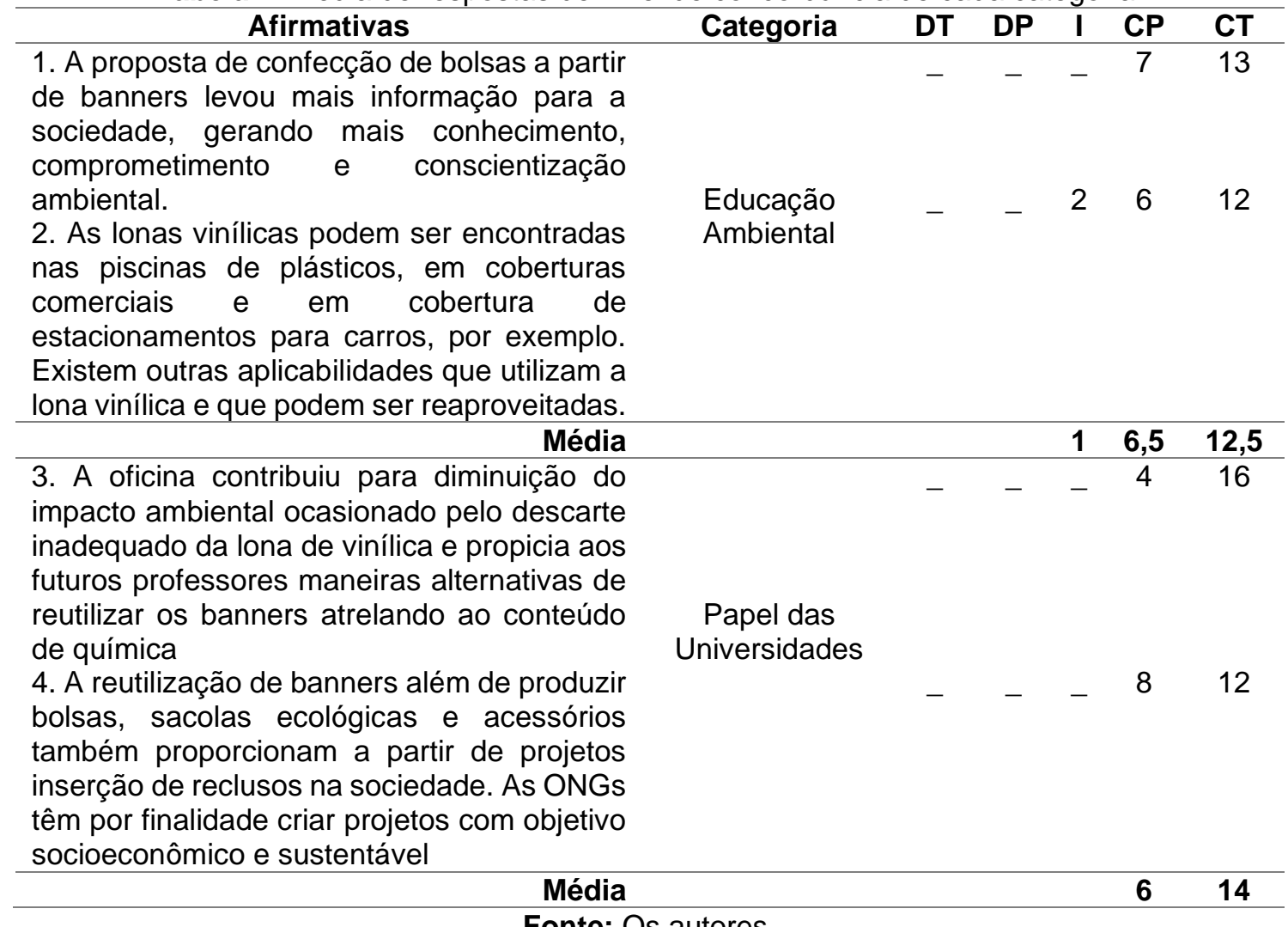

Fonte: Os autores.

*DP: discordo parcialmente; DT: discordo totalmente; I: indiferente; CP: concordo parcialmente; CT: concordo totalmente

Categoria 1. Educação Ambiental (EA)

Nessa categoria apresentaram-se duas afirmativas com a intenção de promover mais informação e comprometimento da sociedade com o meio ambiente a partir do reaproveitamento da lona vinílica (banners). Nesse sentido, na soma das afirmativas obteve-se o seguinte gráfico de concordância dos participantes. Importante ressaltar que foi realizada uma média entre as duas afirmativas da categorização da Educação Ambiental (Figura 2). 


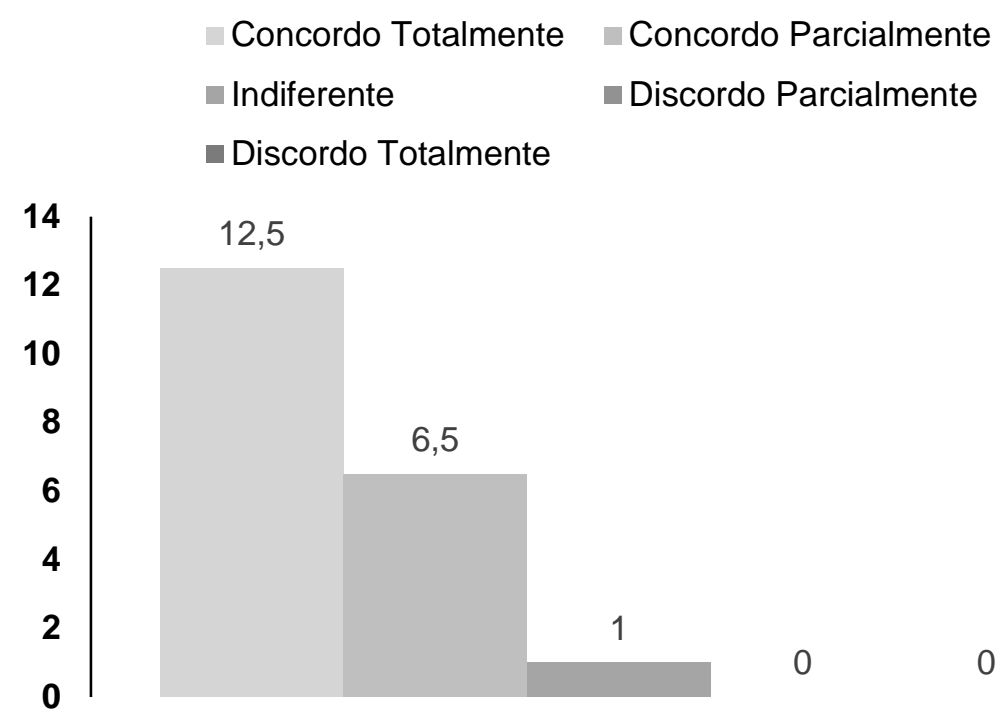

Figura 2: Média das respostas do nível de concordância da categoria EA.

Fonte: Os autores.

A maioria dos participantes "concorda totalmente" com a categorização Educação Ambiental, principalmente quando elas relatam a contribuição de reaproveitar materiais prejudiciais ao meio ambiente e ampliar essa ideia para a comunidade escolar e a sociedade. As falas dos participantes estão contidas no Quadro 1.

Quadro 1: Resposta discursiva dos participantes que concordaram totalmente sobre a categoria $E A$

"A proposta tem pontos positivos porque ela contribui de certa forma para a proteção do meio ambiente usando a ideia como forma de utilização."

"Através da proposta, podemos fazer vários objetos a partir dos banners, isso se tornou possível após a oficina, fazendo com que vejamos com outros olhos os banners."

"Além de incluir a sociedade na educação ambiental, ensinando-os ou incentivando-os na utilização dos $3 R$ s."

"Na era atual é muito importante as novas maneiras de reutilização devido ao fato de termos que evitar esses impactos ambientais."

"É um método diferente e pouco difundido e nos desperta para novos olhares sobre possibilidades de reutilização."

"O trabalho pode ser levado para as comunidades."

"Deveria ser desenvolvida em outros ambientes como escolas."

Fonte: Os autores. 
A preocupação dos participantes em reutilizar o material empregando alternativas para novos usos que, a primeiro momento, não teria outra utilidade. (SILVA; KOMATSU, 2014). A EA, portanto, é uma vertente importante para abordar temas de redução, reutilização e reciclagem (3R's) de resíduos sólidos, popularmente conhecido como lixo, para minimizar o desperdício e o despejo impróprio de materiais e produtos em locais inadequados (ROCHA; ROSA; CARDOSO, 2009).

É valido destacar a importância de integrar a EA as escolas de forma interdisciplinar como processo de educação. (ADAMS, 2012). A lei no 9.795/1999 estabeleceu a Política Nacional de Educação Ambiental (PNEA) e considera que as atividades vinculadas a ela devem ser desenvolvidas na educação em geral e na escolar. Acredita-se que dessa forma, a EA pode mobilizar famílias, crianças e a comunidade para mudanças de hábitos e o comprometimento com o meio ambiente.

Em relação ao nível de concordância "indiferente" e "concordo parcialmente" foram destacadas as palavras sensibilizar e conscientizar nas falas dos participantes, além da aplicabilidade de outros tipos de materiais para o reaproveitamento, bem como, o desconhecimento dela, visto no Quadro 2.

Quadro 2: Resposta discursiva dos participantes que concordaram parcialmente e foram indiferentes sobre a categoria EA

"Porque gerou sim mais informações e incentivo a ideias. Mas acredito que pode levar a uma sensibilização e não conscientização."

"A proposta gerou sim mais informação e conhecimento para sociedade, porém o comprometimento depende de como essas informações e conhecimento afetaram a consciência de cada um."

"Se levar em consideração apenas a confecção de bolsas e não fazer a pessoa ter um novo olhar de que isso é um dos meios para o comprometimento e conscientização ambiental através de palestras, por exemplo, essa informação não terá relevância."

"Sim, muitas vezes quando temos banner em casa fazemos avental para meus tios que são pescador cuidar de peixe."

"Desconheço outras aplicabilidades".

"Sim, como na área de moda (vestuário, acessórios e até revestimento de calçados)."

"Sim, para confecção de tapetes, como proteção de janelas de vidro (para isolação), cortina, avental etc."

Fonte: Autoria Própria

Conforme observado no Quadro 2, os participantes têm um conhecimento prévio de que o banner pode seguir diversas rotas de reutilização, refletindo nos exemplos de aplicabilidade enfatizados por eles. Importante destacar a sensibilização coletiva, pois se acredita que somente dessa forma haverá a conscientização ambiental do indivíduo (SANTOS et al., 2013). Os 
autores ainda ressaltam que o "processo de conscientização é, acima de tudo, comunicação" e "a conscientização não devem ser feitas para, e sim com os sujeitos" (SANTOS et al., 2013, p.108).

O Programa Nacional da Educação Ambiental (2014) destaca que o objetivo da conscientização é a transformação. Acrescenta os autores Santos et al. (2013, p.119) que a "conscientização é tomada no sentido de frear danos ambientais". Nesse sentido, a sensibilização, a conscientização e acima de tudo a mobilização em comunhão com os envolvidos despertará a preocupação com o meio ambiente em que vivem, tornando-as conhecedoras de diferentes formas de reutilização, minimizando a quantidade de rejeitos encaminhados a locais inapropriados.

\section{Categoria 2. O papel das Universidades}

O propósito dessa categoria foi discutir o papel das universidades na formação de cidadãos e sua responsabilidade social enquanto instituição fomentadora de conhecimento e informação. Esta categoria também apresentou duas afirmativas em relação a contribuição de profissionais, como professores, na diminuição dos impactos ambientais ocasionado pelo descarte inadequado da lona vinílica atrelado aos projetos socioeconômicos para a reutilização do material. Dessa forma, obteve-se o seguinte gráfico de concordância dos participantes a partir da média entre as duas afirmativas da categorização 2 (Figura 3).

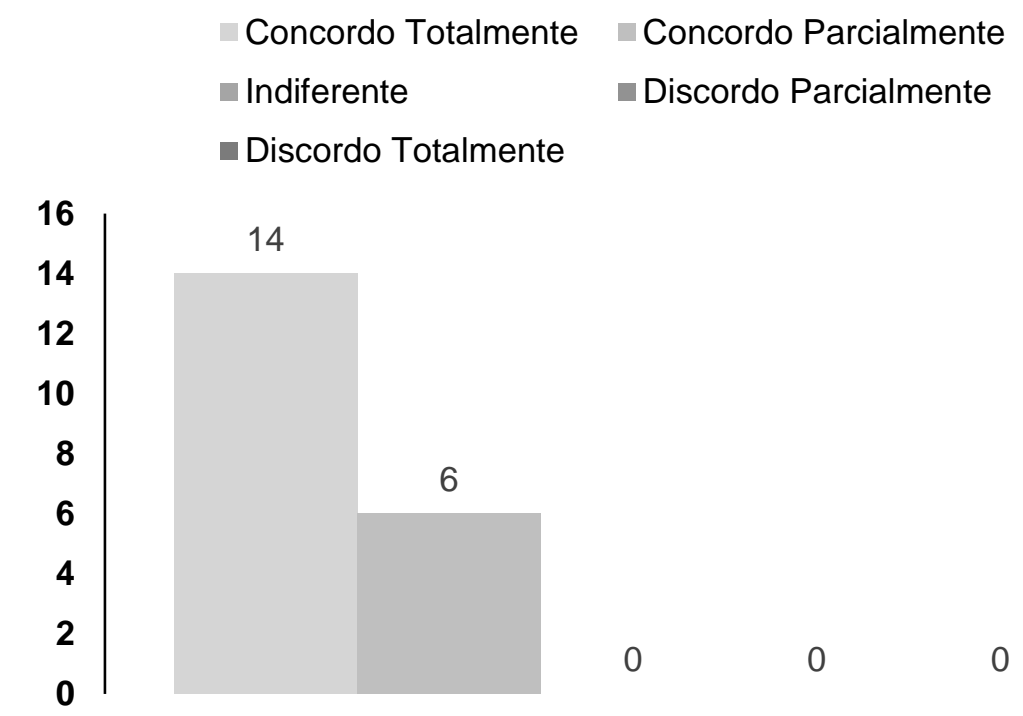

Figura 3: Média das respostas do nível de concordância da categoria Papel das Universidades.

Fonte: Os autores.

A maior parte dos participantes "concorda totalmente" com a categorização Papel das Universidades, principalmente quando elas relatam a importância da confecção de bolsas no aspecto socioeconômico e ambiental agregando o tema ao conhecimento interdisciplinar, podendo ser vistas nas falas dos participantes no Quadro 3. 
Quadro 3: Resposta discursiva dos participantes que concordaram totalmente sobre a categoria Papel das Universidades

"Por que os projetos oportunizam conhecimentos em penitenciarias, por exemplo, possibilitando aquisição econômica futura de forma sustentável."

"É uma forma de renda e também de reabilitação a partir da oportunidade da proposta de trabalho."

"A oficina é uma alternativa para incluir na grade curricular ações de educação ambiental."

"Oferecer novas oportunidades de gerar rendas é fundamental para as pessoas que estão a margem da sociedade."

"A oficina nos remeteu adquirir conhecimento e com isso pode-se perceber que podemos utilizar o banner para confecção de bolsas e assim podendo contribuir com o meio ambiente, tal que o mesmo pode ser atrelado ao conteúdo de química."

"Como aprendemos na oficina, o professor pode relacionar alguns assuntos a ser estudados, como os banners."

Fonte: Autoria Própria

No artigo foi evidente a preocupação não apenas com o descarte inadequado do banner, mas que esse material fosse reaproveitado de modo a gerar renda para as famílias. As Organizações Não Governamentais (ONGs) como a "Tem quem queira" no Rio de Janeiro e "Mãos que criam" em Brasília tem o objetivo em comum que é produzir a partir da lona uma matéria prima para confecção de acessórios, estojos e bolsas. Quem as produzem são presidiários, moradores de comunidades e mulheres de baixa renda (BRASIL, 2016).

Por isso, a necessidade de existir o vínculo entre as Universidades e a sociedade. A partir dos projetos de extensão, o Ensino Superior forma, informa, capacita e compromete a sociedade com as questões envolvendo o meio ambiente, promovendo qualidade de vida (TOMMASIELLO; GUIMARÃES, 2013).

Além disso, a lei 9.795/1999 descreve as Diretrizes Nacionais Curriculares da Educação Ambiental para todos os níveis de ensino. No Ensino Superior é sugerido que a Educação Ambiental, nas diferentes licenciaturas e na pedagogia, seja vista como "atividade curricular, disciplina ou projetos interdisciplinares" (BRASIL, 1999, p.1). Quando o ensino for estabelecido dessa forma o conteúdo de química, por exemplo, poderá ser mais bem contextualizado ao aproximar a realidade vivenciada dos alunos e a partir disso problematizar e propor soluções acerca da temática (MANÉIA, 2016).

No que se refere ao nível de concordância "concordo parcialmente" da Figura 3, o que se observa nas falas dos participantes é a palavra "retardamento" quando nos referíamos a diminuição dos impactos ambientais e de que forma é absorvida as informações fornecidas. 
Quadro 4: Resposta discursiva dos participantes que concordaram parcialmente sobre a categoria Papel das Universidades

"Porque a diminuição em si não ocorre, e sim um retardamento do descarte desse material. Mas é uma iniciativa louvável, visto a durabilidade do material".

"A oficina propicia maneiras alternativas de reutilização, no entanto o impacto para ser diminuído depende do uso de informações adquiridas."

"Não teríamos casos relacionados ao meio ambiente, quando ao problema recorrente a esse material".

"Assim como temos os banners, temos outros materiais prima para confeccionar acessórios: sacolas, bolsas, porta trecos etc".

Fonte: Os autores.

É importante discutir a diferença entre retardo e diminuição. Retardo seria a demora no descarte do material. Diferentemente, diminuição dos impactos ambientais, por exemplo, é quando reaproveitado esse material, a sua utilidade dure por anos, logo seu descarte dificilmente acontecerá.

O Conselho Nacional do Meio Ambiente - CONAMA (1986) considera impacto ambiental:

[...] qualquer alteração das propriedades físicas, químicas e biológicas do meio ambiente, causada por qualquer forma de matéria ou energia resultante das atividades humanas que, direta ou indiretamente, afetam:

I - a saúde, a segurança e o bem-estar da população;

II - as atividades sociais e econômicas;

III - a biota;

IV - as condições estéticas e sanitárias do meio ambiente;

V - a qualidade dos recursos ambientais" (BRASIL, 1986, Art. 1).

O termo foi conceituado para reconhecer as atividades relacionadas e informar a sociedade. Por este motivo, o interesse em promover eventos, feiras, simpósios e encontros para a popularização da ciência propiciando maior participação, consciência, responsabilidade e comprometimento da sociedade. Para isso, as ações das universidades no ensino, pesquisa e extensão, formações complementares em museus e centros de ciências, além do âmbito formal escolar, são meios de sensibilização e desenvolvimento socioambiental.

\section{Considerações Finais}

O desenvolvimento do estudo possibilitou uma análise do conhecimento dos graduandos dos cursos de Licenciatura Plena em Ciências Naturais com Habilitação em Química, Física ou Biologia, Bacharelado em Design, professores e profissionais da área ambiental acerca da contribuição da oficina em promover informações sobre a utilização do banner, descarte e também o comprometimento da sociedade com o meio. 
A partir da oficina voltada para formação destes docentes e futuros docentes pôde-se avaliar as seguintes contribuições da educação ambiental e do papel das Universidades.

Quanto ao âmbito educação ambiental a maioria dos participantes relataram a importância do reaproveitamento dos materiais que são prejudiciais ao meio ambiente, muitas vezes, ocasionadas pela ação antrópica danosa, além da importância em divulgar para as comunidades escolares e locais as consequências do descarte inadequado da lona.

Quanto ao papel das Universidades, a maioria dos participantes relataram que a confecção de bolsas a partir da lona de vinilia trabalha o aspecto socioeconômico, pois este pode ser reaproveitado de maneira a gerar renda e o meio ambiental, pois traz a preocupação do descarte inadequado do banner, sendo necessária a colaboração das universidades na divulgação e a efetiva participação da sociedade.

Assim, a oficina contribuiu para os docentes, futuros docentes e profissionais da área ambiental o aprofundamento dos conhecimentos, reflexão do descarte inadequado e novas estratégias para o ensino e para a (re)utilização de materiais prejudiciais ao meio ambiente.

\section{Referências}

ABIPAST (Brasil) (Org.). Perfil 2014. São Paulo, 2014. 37 p. Disponível em: $<$ http://file.abiplast.org.br/download/links/2015/perfil abiplast 2014 web.pdf $>$. Acesso em: 11 de julho de 2017.

ABRELPE (Brasil). Panorama dos Resíduos Sólidos no Brasil 2015. São Paulo, 2015. 92 p. Disponível em: <http://www.abrelpe.org.br/Panorama /panorama2015.pdf>. Acesso em: 11 julho de 2017.

ADAMS, B. G. A importância da Lei 9.795/99 e das diretrizes curriculares nacionais da Educação Ambiental para docentes. Revista Monografias Ambientais, Santa Maria (RS), v.10, n 10, p.2148-2157, out-dez, 2012.

BARDIN, L. Análise de conteúdo. São Paulo: Edições 70, 2011.

BRASIL. Política Nacional de Educação Ambiental. Lei no 9.795, de 27 de abril de 1999. Brasília, 1999.

BRASIL. Política Nacional de Resíduos Sólidos. Lei no 12.305, de 2 de agosto de 2010

BRASIL. Consumo Sustentável: Manual de educação. Brasília: Consumers International/ MMA/ MEC/ IDEC, 2005. 160 p. ISBN 85-87166-73-5.

BRASIL, 2016. Ministério do Meio Ambiente. Banners viram sacolas ecológicas. Disponível em: http://www.mma.gov.br/informma/item/13203noticia-acom-2016-01-1402.html. Acesso 26 de julho de 2017 
BRASIL, Resolução Conama n. 001, de 23 de janeiro de 1986. Conselho Nacional do Meio Ambiente - CONAMA, Brasília, DF, jun. 1986.

CARDOSO, L.J.S.; VALENTE, V.F.; RODRIGUES, V.T.; PAVALK A.; RODRIGUES, M.N. Alternativas Sustentáveis Para Reutilização De Banners Em Universidade Do Estado Do Pará. Anais do XXXVI Encontro Nacional De Engenharia De Produção. João Pessoa. 2016.

D'AVILA, F.; LENZI, T. Re-utilizar para educar e minimizar problemas socioculturais. In: 13a Mostra da Produção Universitária. Rio Grande, 2014.

HERMES, L.; MORGENSTERN, E. C. Ecobanner: Reaproveitamento sustentável de lonas vinílicas. Blucher Design Proceedings, Belo Horizonte, v. 9, n. 2, 2016.

JUNG, A.A.; SALDANHA, M.A.; GONÇALVES, J.A.; TOCCHETTO, M.R.L.; DIC, C. Projeto relona: reaproveitamento de lonas de banner. Anais do $4^{\circ}$ Fórum Internacional Ecolnovar. 4, 2015, Santa Maria (RS).

MARTINUSSI, J. C.; ROSA, R. P.; GOYA, C. R. Projeto Kid Vinil: um estudo de caso para a reutilização de resíduos de lona vinílica. Anais do 9o Congresso Brasileiro de Pesquisa e Desenvolvimento em Design. São Paulo, 2010.

MANÉIA, A. A responsabilidade ambiental da Universidade na formação humana. Revista Eletrônica em Gestão, Educação e Tecnologia Ambiental, Santa Maria, v. 20, n. 1, p. 274-282, jan-abr. 2016.

MENDES, J. M. G. Dimensões da sustentabilidade. Revista das Faculdades Santa Cruz, v. 7, n. 2, p.49-59, jul./dez. 2009.

MIKHAILOVA, I. Sustentabilidade: evolução dos conceitos teóricos e os problemas da mensuração prática. Revista Economia e Desenvolvimento, Santa Maria, v. 16, p.22-41, 2004. Anual.

MORAES, R. Análise de Conteúdo. Revista Educação, Porto Alegre, v.22, n.37, p. 7-32, 1999.

NAJELISKIA, D. M.; PALHANOB, A. P.; MATOSOC, L. G. Estudo de Viabilidade da Reutilização de Banners de Lona na Produção de Móveis. Revista Sustentabilidade em Debate, Brasília, v. 8, n.2, p. 60-74, a. 2017.

OJEDA, T. F. M. Biodegradabilidade de materiais poliméricos. 2008. 128 f. Tese (Doutorado) - Curso de Agronomia, Programa de Pós Graduação em Ciência do Solo, Universidade Federal do Rio Grande do Sul, Porto Alegre, 2008. Cap. 6. Disponível em: <http://www.lume.ufrgs.br/handle/10183/17265>. Acesso em: 05 jul. 2017.

OLIVEIRA, E. C. A.; SARTORI, R. H.; GARCEZ, T. B. Compostagem. 2008. Agência Embrapa de Informação Tecnológica. Disponível em: $<$ https://www.agencia.cnptia.embrapa.br/Repositorio/Compostagem 000fhc8nf qz02wyiv80efhb2adn37yaw.pdf>. Acesso em: 10 jul. 2017 
PINHEIRO, N. F. S.; ROCHA, A. P.; GAMA, E. P.; LIMA, R. S.; RODRIGUES, A.C.R. Percepção ambiental: uma análise sobre a política dos $3 R$ 's em um colégio estadual na cidade de Palmas - TO. Disponível em < http://www.catolicato.edu.br/portal/portal/downloads/docs gestaoambiental/projetos2011-1/1periodo/Uma analise sobre a politica dos 3Rs em um colegio estadual na cidade de Palmas-TO.pdf >Acessado em 24 mai 2018.

PROGRAMA NACIONAL DE EDUCAÇÃO AMBIENTAL - ProNEA / Ministério do Meio Ambiente, Diretoria de Educação Ambiental; Ministério da Educação. Coordenação Geral de Educação Ambiental. - 5. ed - Brasília : Ministério do Meio Ambiente, 2014. p. 114

REIS, H.B.C. Os impactos da globalização sobre o meio ambiente: uma introdução à análise da Comunicação Social. Revista Contemporânea. Rio de Janerio, v. 1, n 4, p. 181-192, 2005.

ROCHA, J. C.; ROSA, A. H.; CARDOSO, A. A. Introdução à Química Ambiental. São Paulo: Artmed Editora. 2a Ed., 2009. 256 p.

SANTOS, E. R.; FERREIRA, A. C.; SERPE, B. M.; ROSSO, A. J. Uso dos termos consciência, conscientização e tomada de consciência nos trabalhos paranaenses de Educação Ambiental. Revista Educação Pública, Cuiabá, v.22, n. 48, p. 103-123, jan-abr. 2013.

SANTOS, L. C. dos. A questão do lixo urbano e a geografia. Anais do $1^{\circ}$ Seminário de Pós-Graduação em Geografia. Rio Claro: Editora. 2008. p. 10141028. 2008.

SILVA, A.; KOMATSU, R. Conceito dos 3R: um breve referencial para uma empresa sustentável. Revista Interatividade, Andradina (SP), Edição Especial, 1ㅇs. 2014.

SILVA, C. O.; SANTOS, G. M.; SILVA, L. N. A DEGRADAÇÃO AMBIENTAL CAUSADA PELO DESCARTE INADEQUADO DAS EMBALAGENS PLÁSTICAS: Estudo de Caso. Revista Eletrônica em Gestão, Educação e Tecnologia Ambiental, [s.l.], v. 13, n. 13, p.2683-2689, 13 ago. 2013. Universidade Federal de Santa Maria.

TARVARES, J. C. L. Caracterização dos Resíduos Sólidos Urbanos da cidade de Maceió - Al. 2008. 114p. Dissertação (Mestrado em Engenharia: Recursos Hídricos e Saneamento) - Universidade Federal de Alagoas. Centro de Tecnologia, Maceió.

TOMMASIELLO, M. G. C.; GUIMARÃES, S. S. M. Sustentabilidade e o papel da universidade: desenvolvimento sustentável ou sustentabilidade democrática? Revista de Educação do COGEIME, Belo Horizonte, v.22, n.43, jul-dez 2013.

YOSHIDA, C. Competência e as diretrizes da PNRS: conflitos e critérios de harmonização entre as demais legislações e normas. In: JARDIM, A.; YOSHIDA, C.; MACHADO FILHO, J. V. (Ed.). Política Nacional, Gestão e Gerenciamento de Resíduos Sólidos. Barueri: Manole, 2012. 